\title{
GLYCOGEN, PHOSPHORYLASE AND GLYCOGEN SYNTHETASE IN HAMSTER TESTIS DURING POSTNATAL DEVELOPMENT
}

\author{
J.-P. FOUQUET AND S. GUHA \\ Laboratoire de Biologie Cellulaire, Faculté des Sciences de Paris, \\ and Institut d'Histochimie Médicale, Faculté de Médecine, Paris, France
}

(Received 4th Fuly 1968, revised 28th November 1968)

Summary. The distributions of glycogen, phosphorylase and glycogen synthetase were studied in the testes and ductuli efferentes of hamsters aged 1 to 99 days (body weight 3 to $130 \mathrm{~g}$ ). Glycogen was also determined quantitatively.

From Stages IV to VIII of spermatogenesis, the seminiferous tubules of adult hamsters contain considerable amounts of glycogen $(0 \cdot 15$ to $0.2 \%$ of testicular weight), localized in the Sertoli cells and in the lumen of the tubules. Phosphorylase and glycogen synthetase are also present in tubules containing glycogen.

The appearance of glycogen in the seminiferous tubules during the 4th week of life (45-g animals) coincides with the appearance of spermatocytes. Up to the establishment of spermatogenesis (usually 5 th or 6th week; 50 to $60-\mathrm{g}$ animals), a progressive increase in the glycogen content $(0.05$ to $0.07 \%)$ and phosphorylase activity is observed. Glycogen synthetase activity appears at this stage. A sharp rise in glycogen concentration as well as an increase in activity of phosphorylase and glycogen synthetase occurs at puberty. From the 3rd month, the enzyme activities diminish considerably, though the content and cyclic distribution of glycogen remains unchanged.

Rete testis epithelium, though devoid of glycogen, contains phosphorylase at all the stages of development. In the adult, the intratesticular rete testis lumen contains a trace of glycogen and phosphorylase. The proximal portion of the ductuli efferentes is characterized by a massive glycogen accumulation in the epithelium (ciliated cells) as well as in the lumen. Both phosphorylase and glycogen synthetase have a high activity in this organ. Glycogen synthesis in the ductuli efferentes occurs earlier than in the seminiferous tubules.

It seems probable that spermatogenesis and glycogen synthesis are independent of each other.

\section{INTRODUCTION}

Numerous histochemical studies indicate the presence of glycogen in the seminiferous tubules of man (Arzac, 1950; Long \& Engle, 1952; Mancini, Nolazco 
\& de la Balze, 1952; Montagna \& Hamilton, 1952), of deer (Wislocki, 1949), of hamster (Clermont, 1954) and of different domestic and laboratory animals (Nicander, 1957). These data were reviewed by Mann (1964). In spite of a relatively abundant literature on testicular glycogen, no quantitative data are available on this subject. Only Mancini, Narbaitz \& Lavieri (1960) have studied the localization of glycogen in human testis during the postnatal development. Alfano \& Swartz (1955) studied total glycogen in hamster testis during postnatal development, though no data on the quantity or localization were given. As glycogen is abundant in hamster testis (Clermont, 1954), the present study on the localization of glycogen in the testis, particularly in the seminiferous tubules, from birth to maturity, was undertaken and correlated with the quantity of glycogen present. The present report is also concerned with the possible co-relationship of glycogen with spermatogenesis and with the enzymes of glycogen synthesis and breakdown, i.e. glycogen synthetase and phosphorylase.

\section{MATERIAL AND METHODS}

From March to October, hamsters from 1 to 99 days old and some animals of undetermined age (body weight 3 to $130 \mathrm{~g}$ ) were killed by stunning. One testis of each animal was rapidly frozen in liquid nitrogen and the sections were cut in a cold microtome. The other testis was usually utilized for glycogen determination. Some adult hamster testes were fixed in Gendre's fluid to localize glycogen in relation to spermatogenic stages. Sections of either unfixed or fixed tissues were cut in such a way as to obtain the seminiferous tubules, rete testis and efferent ducts in the same section.

Periodic acid-Schiff reaction with dimedone blocking, and occasionally with saliva digestion on fixed tissue sections was utilized for glycogen localization (Lison, 1960). Spermatogenic stages are easily identifiable in fixed tissue sections, so these were often preferred for adult animals. Active phosphorylase and total phosphorylase (active + inactive form), were studied by using the incubation media of Guha \& Wegmann $(1959,1960)$. Polyvinyl pyrrolidone, at a concentration of $10 \%(\mathrm{w} / \mathrm{v})$ was added to all these incubation media. For glycogen synthetase activity, the incubation medium of Sie, Sawyer \& Fishman (1966) was utilized. Glucose-6-phosphate independent form (I-form) of glycogen synthetase was examined by omitting glucose-6-phosphate from the above-mentioned medium. Iodine staining was utilized to visualize the sites of these enzyme activities. Incubation of unfixed sections in glycogen synthetase medium often caused cytolysis, so the unfixed tissue sections, before incubation, were post-fixed overnight in absolute alcohol at $-20^{\circ} \mathrm{C}$. After drying, these sections were incubated for $2 \mathrm{hr}$.

Autoradiographic methods for phosphorylase (Guha \& Wegmann, 1966a) and for glycogen synthetase (Guha \& Wegmann, 1968) were equally utilized for some tissue sections to ensure the specificity of these reactions (see Guha \& Wegmann, 1965).

For glycogen determination, testes of each animal were digested in 2 vol. $30 \%$ potassium hydroxide solution to liberate glycogen. After digestion, glyco- 
gen was precipitated in 2 vol. absolute alcohol. Twice precipitated glycogen was hydrolysed by $2 \mathrm{~N}$-sulphuric acid, neutralized and determined by the glucoseoxidase method of Huggett \& Nixon (1957).

\section{RESULTS}

\section{Testis from birth to maturity}

Sex cords of 1-day hamsters (body weight about $3 \mathrm{~g}$ ), with the exception of a few grains (one to four per cross-section of a cord), are devoid of glycogen. These grains are usually present in the cytoplasmic mass occupying the centre of the cord, though some grains are found in the peripheral cytoplasm of the supporting cells (future Sertoli cells). The central cytoplasmic mass of these cords is formed by the interdigitation of cytoplasm from the supporting cells (Clermont \& Perey, 1957). Gonocytes seem to contain no glycogen (Pl. 1, Fig. 1). Interstitial cells contain a few grains of glycogen. The tunica albuginea, which is thick at this age, has the highest glycogen content and the walls of arterioles also contain moderate amounts of glycogen. Total phosphorylase is present wherever glycogen can be detected. However, in the sex cords, this enzyme is present not only in the glycogen grains but also throughout the central cytoplasmic mass of the cord (Pl. 2, Figs. 8, 9). The active form of phosphorylase is very weak except in the peripherally situated cords, and glycogen synthetase activity (both I- and D-form) could not be detected in these animals.

During the first 2 weeks of post-natal development, glycogen in the tunica albuginea and in the interstitial cells disappears progressively. In the sex cords, some glycogen can still be detected in 8-day animals, and then at the end of the 2nd week it disappears totally (Pl. 1, Fig. 2). In the arteriole wall, glycogen remains unchanged during development. Total phosphorylase activity also diminishes progressively, parallel with the disappearance of the sex cord glycogen. A weak activity, however, persists in the central cytoplasmic mass of the cords but the activity varies from one cord to another.

Towards the end of the 3rd week, lumina appear in the sex cords. Spermatocytes (II) and a few immature spermatids are seen in these animals. Glycogen, in trace amounts, is occasionally detectable in a few tubules, but moderately intense phosphorylase, both active and total, is present in the tubules.

In the 4- to 5-week animals (average weight $45 \mathrm{~g}$ ), spermatocytes and immature spermatids are abundant, the sex cords are transformed into seminiferous tubules and an appreciable amount of glycogen is present. In some tubules of 5-week animals ( 45 to $50 \mathrm{~g}$ ), a second generation of spermatids appears but glycogen disappears almost totally from these tubules, while the tubules containing one generation of spermatids show an increased amount of glycogen (Pl. 1, Fig. 3). Total phosphorylase activity is displayed by most of the tubules. The activity of this enzyme is quite marked in the tubules containing glycogen but weaker or absent in other tubules. The active form of phosphorylase is particularly strong in the glycogen-rich tubules and its activity is only slightly less intense than that of the total form. At the time of puberty, phosphorylase, particularly the active form, increases considerably and 
glycogen synthetase activity becomes detectable in the glycogen-rich tubules. The total glycogen content in these animals varies from 50 to $70 \mathrm{mg} / 100 \mathrm{~g}$ of testis.

The advent of spermatogenesis in the 6 -week animals (body weight 50 to $60 \mathrm{~g}$ ) is marked by a rapid increase in the glycogen content (about $150 \mathrm{mg} / 100 \mathrm{~g}$ of testis). The distribution of glycogen in mature animals follows a cyclic pattern. Glycogen appears in the Sertoli cells of the tubules at Stage IV of spermatogenesis (stages defined according to Clermont, 1954), and then increases considerably, both in the Sertoli cells and in the lumen of the tubules, reaching a maximum at Stage VII. Often the release of spermatozoa at Stage VIII is accompanied by a sudden diminution of glycogen in most of the Sertoli cells, but the lumen still contains a small quantity. Glycogen disappears totally at Stage IX and reappears at Stage IV of the following cycle (PI. 1, Figs. 4, 5, 6).

Parallel with the increase of glycogen, the activities of phosphorylase and of glycogen synthetase increase rapidly and reach their maximum level in 6- to 8 -week animals (body weight 60 to $75 \mathrm{~g}$ ). The active form of phosphorylase displays an intense reaction. Its activity is only slightly inferior to the total activity and it appears to be superimposed on the glycogen in the Sertoli cells and in the lumen of the seminiferous tubules from Stages IV to VIII. A weak phosphorylase activity is often detectable in the tubules from Stages I to III, when they do not appear to contain glycogen. Glycogen synthetase activity is always weaker than that of phosphorylase and is displayed only by those tubules which contain glycogen (Pl. 2, Fig. 14).

In hamsters aged 2 to 4 months, glycogen concentration increases very slowly (150 to $200 \mathrm{mg} / 100 \mathrm{~g}$ of testis), while phosphorylase diminishes very rapidly from the $3 \mathrm{rd}$ month (body weight $>75 \mathrm{~g}$ ). Its presence becomes very fluctuating and at times glycogen-rich tubules show little or no activity. This is even more frequent for active phosphorylase, which is irregular and present only in the periphery of the tubules. By contrast, 'Sertoli cell plugs' at the junction of the seminiferous tubules and the rete testis (for description, see Roosen-Runge, 1961), show a strong phosphorylase activity (Pl. 2, Fig. 13). During the same period, glycogen synthetase activity, though more regular, diminishes considerably.

Quantitative data obtained on testicular glycogen are summarized in Textfig. 1. The quantity of glycogen, calculated as $\mathrm{mg}$ of glycogen $/ 100 \mathrm{~g}$ testicular wet weight, is plotted against the body weight of each animal. The data on new born to 2-week-old animals are not included here, because most of the glycogen at this age is present in elements other than the sex cords. Animals showing normal mature spermatozoa in the epididymal lumen are considered as mature. The quantitative data on the increase of glycogen content during the maturation period (50- to 60-g animals) are in good agreement with the histochemical findings.

\section{Rete testis}

From birth to maturity, no glycogen can be detected in the epithelium of the intratesticular and extratesticular portion of the rete testis but phosphorylase, particularly in the form of total activity, is always present. Active phosphorylase 
is predominant during the first 3 weeks. This form then diminishes and in 4- to 5-week animals the inactive form predominates. Total phosphorylase in rete testis of maturing and mature testes is always present, weak or strong, irregular according to zone, and with individual variation. Active phosphorylase, when present, is extremely weak. From the 6th week, a small quantity of glycogen and phosphorylase activity associated with it, is observed in the lumen of the intratesticular rete testis, but never in the lacuna of the extratesticular portion.

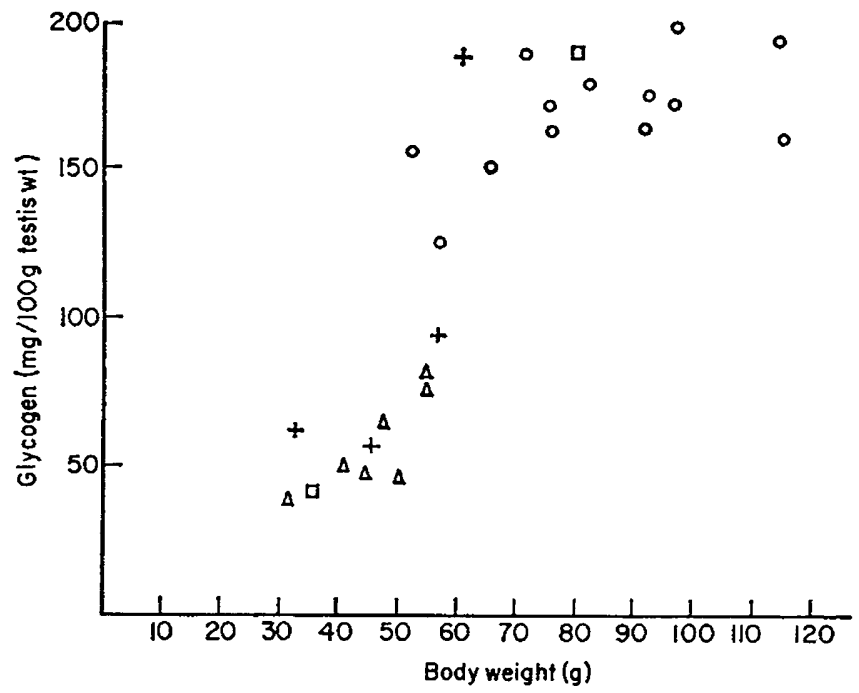

TexT-FIG. 1. Glycogen in hamster testes, calculated as $\mathrm{mg} / 100 \mathrm{~g}$ of testicular weight, is plotted against the body weight of an individual animal. $\square$, Seminiferous tubules reached spermatocyte stage only; $\Delta$, tubules show immature spermatids only; + , some tubules of these animals have two generations of spermatids but no spermatozoa; $O$, mature animals with spermatozoa both in testes and in epididymal lumen. Note the presence of two immature animals with high glycogen content.

\section{Ductuli efferentes}

From birth to 3 weeks, the epithelium does not contain glycogen, but total phosphorylase, with the weaker active form, can be detected. From the 4th week, glycogen appears in some of the cells, where it accumulates rapidly to fill up the cytoplasm completely. These cells seem to be ciliated. They are particularly abundant in the portion of the ducts proximal to the testis (Pl. 1, Fig. 7) and are very rare in the portion of the ducts distal to the testis. At the same time, glycogen accumulates in the lumen of the proximal portion of the ducts. During this period, phosphorylase activity increases and glycogen synthetase activity appears. The sites of activity of both enzymes can be superimposed on that of glycogen. The activity of both enzymes can be equally confirmed by autoradiography.

In the maturing as well as in mature animals, the following results are obtained: glycogen is abundant in the ciliated epithelial cells and in the lumen of the proximal zone. It is absent, except in rare epithelial cells, in the distal zone. In the proximal zone, glycogen synthetase activity is strong in the basal 
part of the epithelium and in the lumen (Pl. 3, Fig. 17). Total phosphorylase is particularly intense, but active phosphorylase displays a variable intensity (Pl. 3, Fig. 15) and, at times, the cells richest in glycogen are deprived even of the activity of this form. In the distal zone, glycogen synthetase is totally absent and phosphorylase is present mainly in the basal part of the cells (Pl. 3, Fig. 16).

Traces of glycogen and intense phosphorylase activity are always observed in the supporting tissue of the epithelial cells composed of muscle fibres and connective tissue.

\section{DISCUSSION}

This paper includes only data obtained on animals studied from March to October, because testicular regression occurs in the hamster from November to February (Czyba, Girod \& Durand, 1964).

Glycogen distribution was studied by the periodic acid-Schiff method with dimedone treatment applied between the periodic acid and the Schiff's reagent. Occasional saliva digestion on testis sections fixed with Gendre's fluid also showed a complete disappearance of PAS-dimedone-stained material. In different organs, only mucin and glycogen staining by Schiff's reagent were not blocked by dimedone. In the absence of mucin in the testis, it could, therefore, be assumed that after dimedone blocking only glycogen was observed. Sections of both unfixed and fixed testes showed similar localization of glycogen. Both methods of preparation showed granular glycogen, and in fixed tissue sections these grains were very coarse.

A comparison of the distribution of glycogen in hamster and in human testes shows the following differences: (a) in hamster sex cords, glycogen is present only in the supporting cells (Sertoli cells), while in man, glycogen is present only in the gonocytes of the sex cord (Mancini et al., 1960); (b) in adult hamsters, glycogen is present in the Sertoli cells (Pl. 1, Fig. 4) and absent in the germinal cells, while in man, glycogen is present in the Sertoli cells, where it appears only after puberty, and the germinal cells (spermatogonia, spermatocytes, and immature spermatids) also contain some glycogen.

The presence of glycogen exclusively in the Sertoli cells was also observed (Fouquet, 1968) in an electron microscopic study. A valid comparison of the cyclic pattern of glycogen distribution is difficult, because no paper published on human testicular glycogen correlates it with spermatogenic stages. However, according to Montagna \& Hamilton (1952), "The cytoplasm of those Sertoli cells which are associated with spermatozoa seem to contain less glycogen than those which are free of maturing spermatozoa". From this, it appears that more glycogen is present in the human seminiferous tubules at stages corresponding to Stages IX to XIII of the hamster; this is in marked contrast"to the hamster where glycogen is observed only in Stages IV to VIII. This finding is in contradiction with that of Alfano \& Swartz (1955) who consider that the distribution of glycogen in hamster testis is similar to that in man.

As in the hamster, the presence of glycogen in the lumen of the seminiferous tubules was equally observed in the human testis (Montagna \& Hamilton, 
1952), and in deer during the period of sexual inactivity (Wislocki, 1949). Glycogen, once liberated in the lumen, is probably broken down to small molecules very rapidly, since very little glycogen is observed in the lumen of the intratesticular rete testis and none in the extratesticular portion.

The quantity of glycogen in adult hamster testis appears quite important $(0.15$ to $0.2 \%$ of testicular weight $)$, particularly if it is considered that only about half of the tubules contain glycogen. The significance of the presence of glycogen and its role in spermatogenesis are difficult to explain as general metabolic phenomena because much variation is observed in the cycle of production and in the amounts occurring in different species. It is known that FSH stimulates Sertoli cells, which, in their turn, control the differentiation of germinal cells (Lacy, 1967). Different hormones also cause modification of glycogen content (Jeffrey, Cavazos, Feagans \& Schmidt, 1967), but nothing indicates the indispensability of glycogen for spermatogenesis. It is evident from our quantitative data (see Text-fig. 1) that some hamsters, showing an abnormal delay in spermatogenesis, have a high testicular glycogen content. Thus, in spite of a certain correlation between the synthesis of glycogen and of spermatogenesis, these two phenomena may be independent of each other. The control of germinal cell differentiation by seminiferous tubule glycogen appears improbable. Experiments are now being carried out to dissociate these two factors in experimental conditions.

Glycogen is found to be abundant in the lumen of the ductuli efferentes when unfixed tissue sections are utilized. Fixed tissue sections show much less glycogen. This may be due to loss of glycogen from the lumen during fixation. However, in the former case, the possibility of mechanical diffusion of glycogen from the glycogen-rich epithelial cells cannot be discarded. Glycogen in the lumen disappears progressively. Very little glycogen is observed in the lumen in the mid-portion of the ducts and none in the lumen of the distal end. Phosphorylase associated with this glycogen may be responsible for its disappearance. Glycogen liberated in the lumen cannot be directly utilized by spermatozoa (Mann, 1964), but its degradation products produced by phosphorylase and by other unknown glucosidases may be accessible to spermatozoa. It seems probable that, in many mammals, the spermatozoa, both when released and in different regions of the excretory ducts, have oligosaccharide elements at their disposal before having access to fructose or to glucose secreted by the accessory glands (Mann, 1964; Fouquet, 1966). Montorzi \& Burgos (1967) have indicated the presence of glycogen in the epithelium of the ductuli efferentes, but the striking difference of epithelial glycogen between the proximal and the distal portion seems to have escaped their attention.

The presence of glycogen in the testis and in the efferent ducts led to the present study of phosphorylase and glycogen synthetase activity, in order to understand the mechanism of glycogen synthesis and breakdown in these organs. Guha \& Wegmann (1966b) found that phosphorylase activity is quite strong in 8-day guinea-pig testis and diminishes progressively with maturation. In young mature animals, phosphorylase shows a moderate activity. Phosphorylase activity in hamster testis increases progressively with maturation and the highest activity is observed just after puberty, but the localization of 
this enzyme in immature and mature animals of both species is identical. The only exception is that phosphorylase in the guinea-pig is not associated with any definite stage, while in the hamster, it is present only in certain spermatogenic stages (Stages I to IX). In spite of a higher glycogen content, the hamster testis, in all the stages of development, shows a weaker activity than that of the guinea-pig.

Glycogen synthetase activity has a late appearance in the developing testis. This activity appears only when a certain amount of glycogen is detectable in the seminiferous tubules. As phosphorylase is present in the tubules from the very beginning of glycogen synthesis, it seems that this enzyme, in spite of its predominating glycogenolytic role, may take part in synthesis of testicular glycogen. Illingworth, Brown \& Cori (1961) found that purified phosphorylase (after a lag period) can synthesize glycogen from glucose-1-phosphate in the absence of primer glycogen. They considered that phosphorylase may play a part in glycogen synthesis.

In older animals, glycogen cycle and content remaining constant, the diminution of phosphorylase and glycogen synthetase may indicate that some other unidentified factor or factors also take part in the regulation of synthesis and breakdown of testicular glycogen.

\section{ACKNOWLEDGMENTS}

We are grateful to Professor T. Mann of the University of Cambridge for his critical evaluation of the manuscript.

\section{REFERENCES}

Alfano, G. A. \& Swartz, E. (1955) Distribution and total testicular glycogen at various postnatal ages of golden hamster. (Abstract). Anat. Rec. 122, 447.

Arzac, J. B. (1950) Glycogen in human testicular biopsy material. 7. clin. Endocr. Metab. $10,1465$.

Clermont, Y. (1954) Cycle de l'épithélium séminal et mode de renouvellement des spermatogonies chez le hamster. Revue can. Biol. 13, 208.

Clermont, Y. \& Perey, B. (1957) Quantitative study of the cell population of the seminiferous tubules in immature rats. Am. J. Anat. 100, 241.

Czyba, J. C., Girod, C. \& Durand, N. (1964) Sur l'antagonisme épiphyso-hypophysaire et les variations saisonnières de la spermatogenèse chez le hamster doré (Mesocricetus auratus). C. r. Séanc. Soc. Biol. 158, 742.

FouQueT, J.-P. (1966) Identification du D-glucose dans les organes accessoires de la reproduction chez quelques rongeurs. C. r. hebd. Séanc. Acad. Sci., Paris, 262, D2373.

Fouquer, J.-P. (1968) Etude infrastructurale du cycle du glycogène dans les cellules de Sertoli du hamster. C. r. hebd. Séanc. Acad. Sci., Paris, 267, D545.

GuHa, S. \& Wegmann, R. (1959) Études sur l'activité phosphorylasique I. Une nouvelle méthode de mise en évidence de la phosphorylase. Annls Histochim. 4, 103.

Guha, S. \& Wegmann, R. (1960) Etudes sur l'activité phosphorylasique. IV. Activation in vitro par la protamine. Annls Histochim. 5, 1.

GuHa, S. \& WEGManN, R. (1965) Histoautoradiographic localization of phosphorylase activity. 7. Histochem. Cytochem. 13, 148.

Guha, S. \& Wegmann, R. (1966a) The use of $\mathrm{C}^{14}$-labelled substrate in histochemical demonstration of different forms of phosphorylase. Histochemie, 6,350 .

Guha, S. \& Wegmann, R. (1966b) Activité phosphorylasique dans le testicule et dans l'épididyme de cobaye, avant et après la maturation sexuelle. Annls Histochim. 11, 213.

GuHA, S. \& Wegmann, R. (1968) Histochemical studies on glycogen synthetase activity by autoradiographic method. Histochemie, 13, 207.

Hugget, A. St. G. \& Nixon, D. A. (1957) Use of glucoseoxidase, peroxidase, and o-dianisidine in determination of blood and urinary glucose. Lancet, $\mathbf{i i}, 368$. 
Illingworth, B., Brown, D. H. \& Cori, C. F. (1961) The de novo synthesis of polysaccharide by phosphorylase. Proc. natn. Acad. Sci. U.S.A. 47, 469.

Jefrrey, J. E., Cavazos, L. F., Feagans, W. M. \& Schmidt, F. H. (1967) The interaction of estrogen, testosterone and chorionic gonadotrophin ( $\mathrm{HCG}$ ) on the reproductive system of the male hamster. I. Sexually active animals. Acta anat. 66, 387 .

LACY, D. (1967) The seminiferous tubule in mammals. Endeavour, 26, 101.

Lison, L. (1960) Histochimie et cytochimie animale, 3rd edn. Gauthier-Villars, Paris.

Long, M. E. \& Engle, E. T. (1952) Cytochemistry of the human testis. Ann. N.Y. Acad. Sci. 55, 619.

Mancin, R. E., Narbaitz, R. \& Lavieri, J. C. (1960) Origin and development of the germinative epithelium and Sertoli cells in the human testis; cytological, cytochemical and quantitative study. Anat. Rec. 136, 477.

Mancini, R. E., Nolazco, J. \& de la Balze, F. A. (1952) Histochemical study of the normal adult human testis. Anat. Rec. 114, 127.

Mann, T. (1964) The biochemistry of semen and of the male reproductive tract. Methuen, London.

Montagna, W. \& Hamilton, J. B. (1952) Histological studies of human testes. II. The distribution of glycogen and other $\mathrm{HIO}_{4}$-Schiff reactive substances. Anat. Rec. 112, 237.

Montorzi, N. M. \& Burgos, M. H. (1967) Uptake of colloidal particles by cells of the ductuli efferentes of the hamster. Z. Zellforsch. mikrosk. Anat. 83, 58.

NrCANDER, L. (1957) A histochemical study on glycogen in the testis of domestic animals with special reference to variations during the spermatogenetic cycle. Acta neerl. Morph. 1, 233.

Roosen-Runge, E. C. (1961) The rete testis in the albino rat, its structure, development, and morphological significance. Acta anat. 45, 1.

Sie, H. G., Sawyer, D. \& Fishman, W. H. (1966) Enzymorphologic demonstration of glucose-6phosphate dependent glycogen synthetase in mouse liver. F. Histochem. Cytochem. 14, 247.

WisLocki, G. B. (1949) Seasonal changes in the testes, epididymis, and seminal vesicles of deer investigated by histochemical methods. Endocrinology, 44, 167. 


\section{EXPLANATION OF PLATES}

Figures, unless mentioned otherwise, are obtained from unfixed tissue sections.

\section{PLATE 1}

FIG. 1. Glycogen in a sex cord and tunica albuginea (below left) of a 1-day-old hamster; PAS-dimedone with toluidine blue counterstain. $\times 250$.

Fig. 2. Sex cord of a 2-week-old hamster showing absence of glycogen by PAS-dimedone staining; toluidine blue counterstain. $\times 160$.

Fig. 3. Two tubules in a 4-week-old hamster $(47 \mathrm{~g})$. The tubule showing one generation of spermatids (above) shows a certain amount of glycogen in the periphery, while the tubule containing two generations of spermatids (below) is practically devoid of glycogen. Glycogen has escaped from a tubule (arrow) due to mechanical disruption of the boundary tissue. PAS-dimedone toluidine blue. $\times 160$.

Fig. 4. Glycogen in a Sertoli cell (arrow) in a tubule at Stage VIII of spermatogenesis in an adult hamster. Stage III is devoid of glycogen. Testis fixed with Gendre's fluid, stained with PAS and counterstained with haemalum. $\times 160$.

Fig. 5. Tubule at stage $\mathrm{V}$ of spermatogenesis showing glycogen in the Sertoli cells and in the lumen along the sperm tail. Tissue section fixed with Gendre's fluid, stained with PAS and counterstained with haemalum. $\times 160$.

FIG. 6. Two tubules at stages IX (left) and III (right) showing absence of glycogen by PAS staining. Tissue section fixed with Gendre's fluid; haemalum counterstaining. $\times 160$.

Fig. 7. Proximal portion of three ducts of the ductuli efferentes showing different amounts of glycogen. The duct at the extreme left is practically devoid of glycogen, while the duct in the extreme right contains glycogen both in the epithelium and lumen. $\times 64$.

\section{PLATE 2}

FIG. 8. Total phosphorylase activity in 1-day hamster; strong activity in the rete testis, in ductuli efferentes (arrow) and weak activity in the sex cords. $\times 40$.

FrG. 9. Total phosphorylase in sex cords. Note intense activity in the glycogen grains and weak activity in the cytoplasmic mass. $\times 250$.

Fig. 10. Active phosphorylase in a 3-week hamster testis. In the rete testis, activity is intense in the intratesticular portion and weak in the extratesticular portion. Sex cords have a very weak activity. $\times 40$.

Fig. 11. Total phosphorylase in the section adjacent to that in Fig. 10. Note much stronger activity in the sex cords and similar reactions in the rete testis. $\times 40$.

Fig. 12. Total phosphorylase in the tubule of a 2-month-old hamster. Activity is moderate in the basal part of some of the Sertoli cells and in the glycogen grains within the sperm tails. $\times 64$.

Fig. 13. A tubule of adult hamster before opening into rete testis. Note stronger activity in the Sertoli cell plug (arrow). $\times 64$.

Frg. 14. Glycogen synthetase in a seminiferous tubule containing spermatozoa. Spermatozoa appear dark because of heavy iodine staining. Note glycogen mass formed between the sperm tails. $\times 160$.

\section{PLATE 3}

Fig. 15. Proximal part of ductuli efferentes of adult hamster showing active phosphorylase reaction both in the epithelium and in the lumen. Total phosphorylase of this organ is slightly more intense. $\times 64$.

Frg. 16. Distal part of ductuli efferentes showing total phosphorylase activity in the basal part of epithelium. $\times 102$.

FIG. 17. Glycogen synthetase activity in a proximal efferent duct. Epithelium and some glycogen grains in the lumen contain this activity. $\times 160$. 

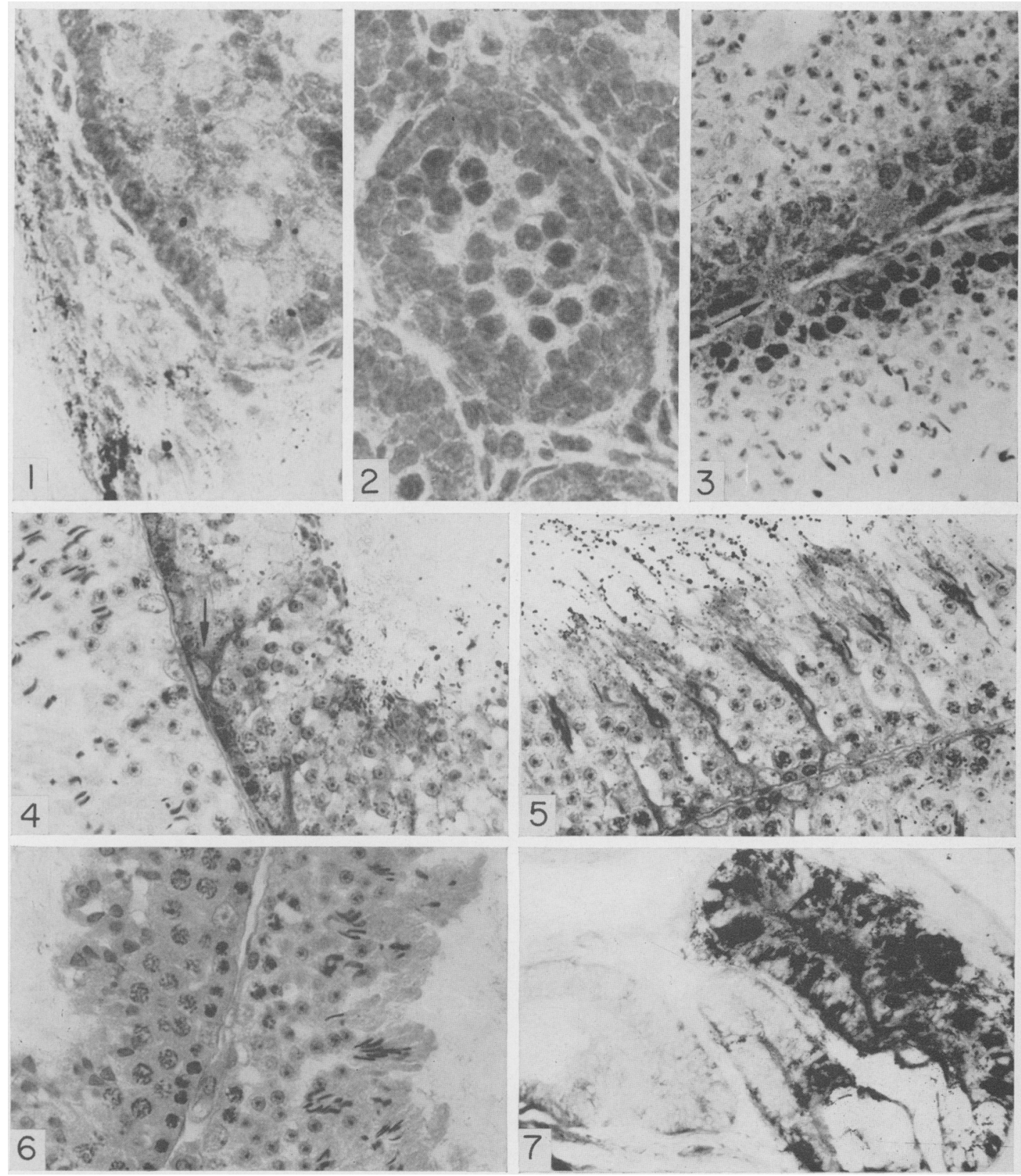
PLATE 2
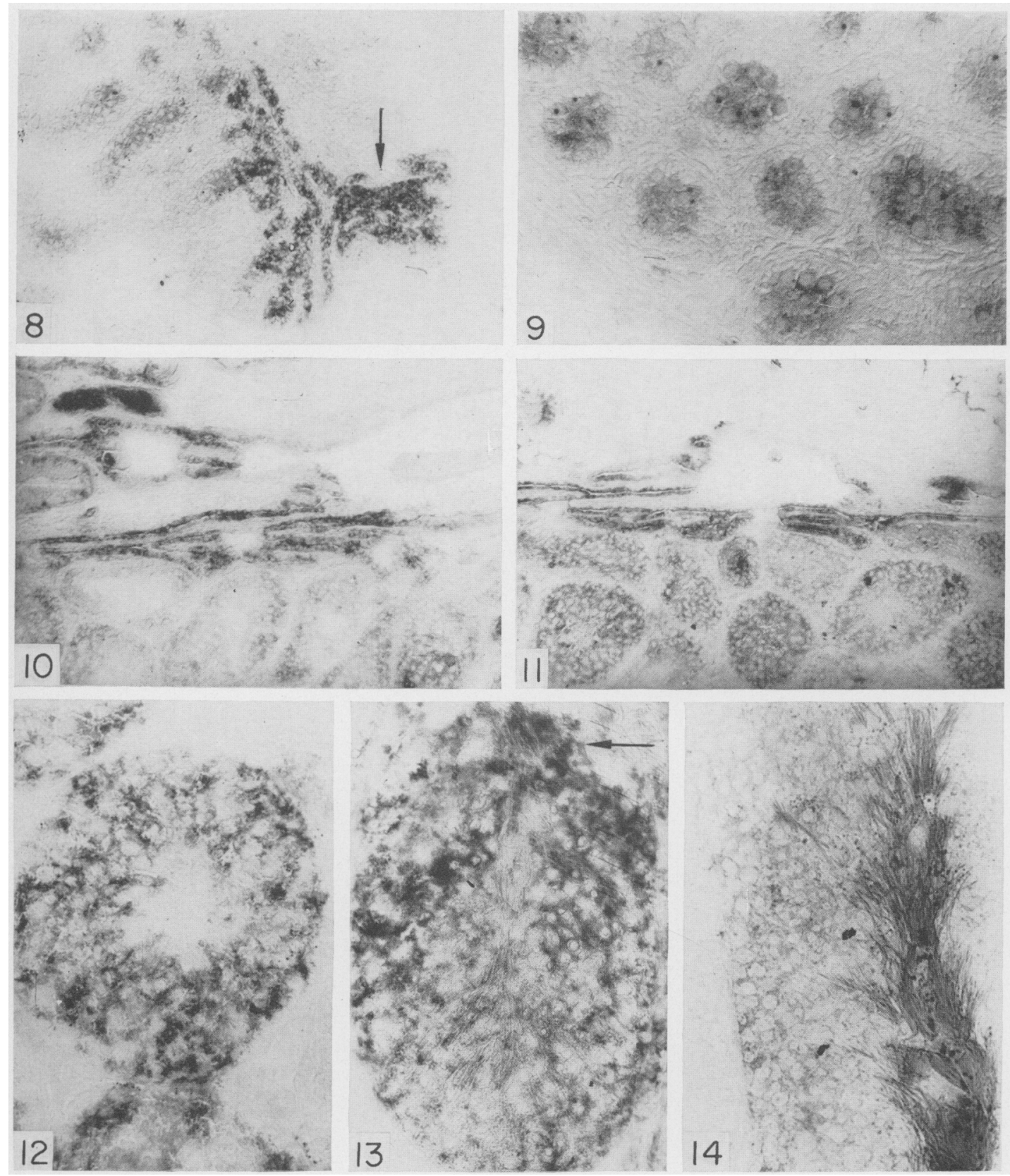
PLATE 3
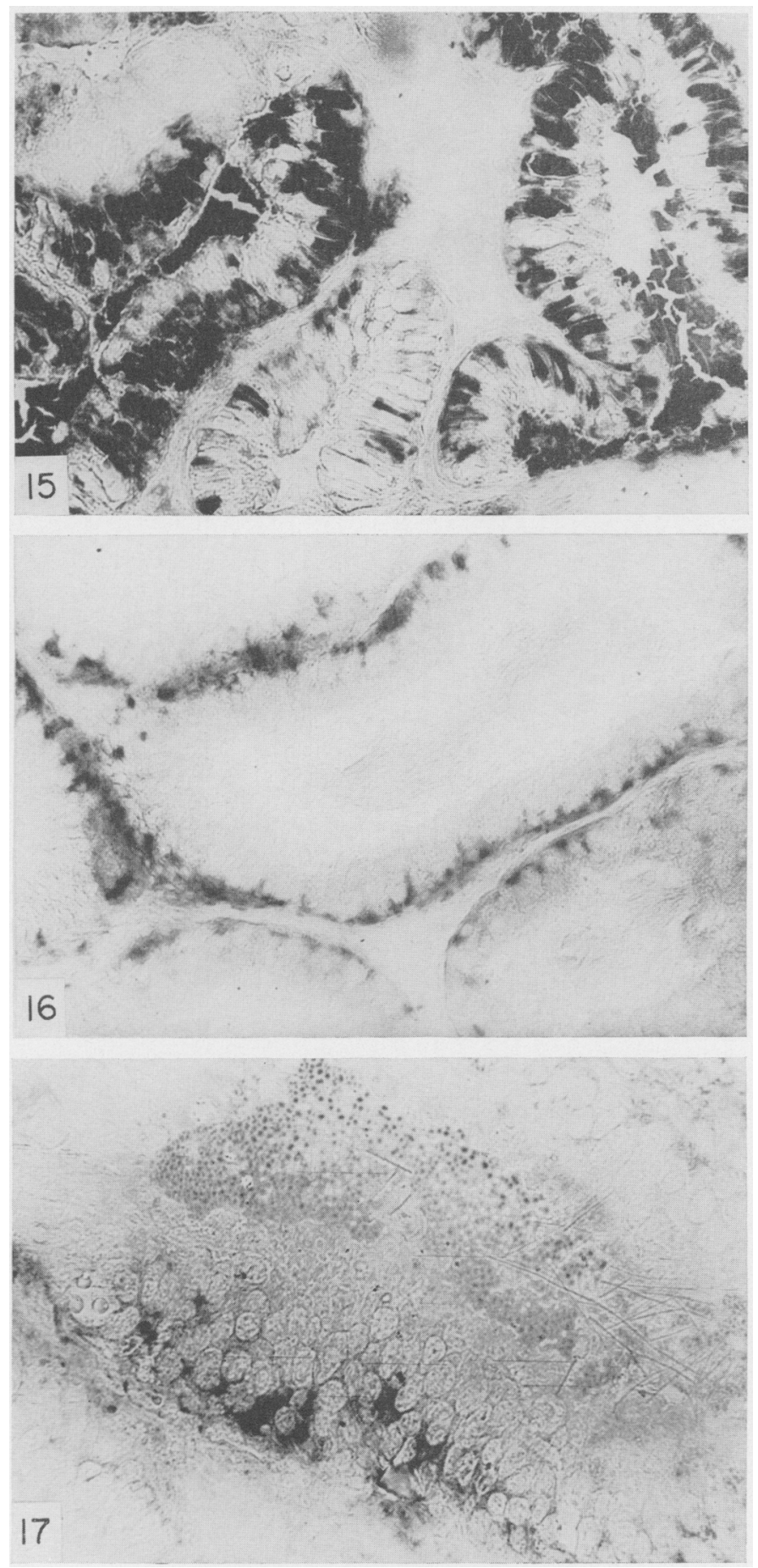